\title{
Stimulatory Effect of Octopamine on Juvenile Hormone Biosynthesis in Honey Bees (Apis mellifera): Physiological and Immunocytochemical Evidence
}

\author{
HANNES KAATZ, ${ }^{*} \uparrow$ STEFAN EICHMÜLLER,, SABINE KREISSL $\ddagger$
}

\begin{abstract}
The effect of octopamine on the activity of corpora allata of adult worker honey bees has been examined in vitro and correlated to the local distribution of this biogenic amine in brain and retrocerebral complex as studied immunocytochemically by means of an highly specific antiserum. Octopamine causes a dose-dependent increase in juvenile hormone release from corpora allata. Maximum increase is obtained with concentrations of $10^{-6} \mathrm{M}$ in nurse and foraging bees by 45.3 or $32.3 \%$, respectively. Octopamine-like immunoreactivity occurs in about 45 somata of the median neurosecretory cells in the pars intercerebralis of the bee brain. They project via immunopositive nervus corporis cardiaci $I$ into the corpora cardiaca, where interspersed varicose structures and 8-10 cell bodies in the ventral part of this gland are stained. A network of immunoreactive fine varicose nerve fibres surrounds each gland cell of the corpora allata. Immunoreactivity in these neuronal structures is detectable if bees were starved over night, a condition in which corpora allata elicit the highest juvenile hormone production ever observed in bees. Both, the stimulatory effect of octopamine and the presence of immunoreactive nerve fibers in the corpora allata, strongly indicate a physiological role of this biogenic amine in the regulation of juvenile hormone biosynthesis in adult honey bees.
\end{abstract}

Apis mellifera Octopamine Immunocytochemistry Juvenile hormone biosynthesis Corpora allata Corpora cardiaca Neurosecretory cells

\section{INTRODUCTION}

Metamorphosis and reproduction are controlled in most insect species by the juvenile hormones $(\mathrm{JH})$, sesquiterpenoids produced by the corpora allata (CA). Although the innervation of these endocrine glands is anatomically complex and has not been completely described for any species (Thompson and Tobe, 1990), it is known that the nervous system exerts considerable influence on the biosynthesis of $\mathrm{JH}$. The activity of the CA is regulated by a variety of inhibitory and stimulatory humoral and neuronal factors originating mainly from the insect brain (Tobe and Stay, 1985). During the last few years, neuropeptides acting as allatotropins or allatostatins have been isolated from brains of a few insect species (Katoaoka et al., 1989; Pratt et al., 1989, 1991; Wood-

\footnotetext{
*Institut für Biologie, Technische Universität Berlin, Franklinstr. 28/29, 10587 Berlin, Germany and Center for Insect Science, University of Arizona, Tucson, AZ, U.S.A.

$\dagger$ To whom correspondence should be addressed.

†Institut für Neurobiologie, Freie Universität Berlin, Königin-LuiseStraße 28-30, 14195 Berlin, Germany.
}

head et al., 1989; Kramer et al., 1991; Duve et al., 1993). Besides these allatoregulatory peptides, another group of physiologically active brain substances, the biogenic amines, has been shown to be involved in the regulation of JH biosynthesis. Especially octopamine, that appears to function as a neurohormone, a neurotransmitter and a neuromodulator in insects (Evans, 1985; Agricola et al., 1988; Erber et al., 1993), enhances JH release from $\mathrm{CA}$ in the locust Locusta migratoria (Lafon-Cazal and Baehr, 1988) and inhibits $\mathrm{JH}$ release in the cockroach Diploptera punctata (Thompson et al., 1990).

In honey bees (Apis mellifera L.) as well as in other hymenoptera, regulatory factors of $\mathrm{JH}$ biosynthesis are not yet known, although this hormone plays a central role in the control of queen and worker caste determination (Rachinsky and Hartfelder, 1990) and in the control of the workers age-depedent task performance (Robinson, 1992) and reproduction (Kaatz et al., 1992a; Robinson et al., 1992). The biogenic amines dopamine, noradrenaline, serotonin and octopamine are found in large amounts in the central nervous system of adult honey bees (Mercer et al., 1983; Mercer 1987; Fuchs 
et al., 1989; Brandes et al., 1990; Taylor et al., 1992). Their levels are affected by environmental and genetic factors (Harris and Woodring, 1992) and influence neuronal activity and behavior in adult workers (Bicker and Menzel, 1989; Erber et al., 1993). In the present paper we examined the effect of octopamine on honey bee CA activity and localized the topographical distribution of this major biogenic amine in the brain and the retrocerebral complex using a specific antiserum (Eckert et al., 1992) to gather insight into the complex mechanisms that influence $\mathrm{JH}$ biosynthesis, which in turn primarily generates $\mathrm{JH}$ titres (Huang et al., 1991) and finally exerts its numerous physiological and morphogenetic functions in honey bees.

\section{MATERIALS AND METHODS}

\section{Honey bees}

Worker honey bees (Apis mellifera L.) were taken from queenright two-storey hives. Adult workers of known age were obtained from combs with sealed brood kept in an incubator at $34.5^{\circ} \mathrm{C}$ and $80 \%$ relative humidity. Newly emerged workers were labelled with coloured markers and introduced into test colonies. Nurse bees were removed from combs with open brood cells and determined by age ( 6 days) and fully developed hypopharyngeal glands (Maurizio, 1954). Foragers were caught at the hive entrance after returning from foraging flight and recognized by their pollen loads or by paint marks which they received at an artificial food source.

\section{JH biosynthesis}

Rates of $\mathrm{JH}$ release by the CA were measured by an in vitro radiochemical assay originally described by Pratt and Tobe (1974) and modified for application to adult honey bees (cf. Hildebrandt and Kaatz, 1992). Dissection and incubation of CA were carried out in a defined, honey bee-specific culture medium (Kaatz et al., 1985) lacking L-methionine and bovine serum albumin and supplemented with $0.7 \mathrm{mM}$ L-leucine. One or two pairs of glands each were collected in capped glass culture dishes in $50 \mu 1$ methionine-free medium. After a preincubation period of up to $30 \mathrm{~min}$, the medium was replaced by $50 \mu 1$ medium containing $100 \mu \mathrm{M} \mathrm{L-}-{ }^{3} \mathrm{H}-$ methyl-]methionine (New England Nuclear, sp. act. $7.4 \mathrm{GBq} / \mathrm{mmol}$ ). Glands were incubated at $34.5^{\circ} \mathrm{C}$ in the dark and gently shaken $(45 \mathrm{rpm})$ in medium for $3 \mathrm{~h}$ to determine basal rates of JH release. Subsequently for another $3 \mathrm{~h}$, the CA were transferred into medium containing brain extracts or octopamine or into control medium. In vitro synthesized JH III, which is the only naturally occurring homologue in honey bees (Rembold, 1987), was extracted from the incubation medium via rapid partition assay (Feyereisen and Tobe, 1981) and quantified by liquid scintillation spectrometry.

\section{Brain extracts}

Brains of foraging bees were dissected out of the frontally opened head capsule and placed into cold distilled water. After sonication $2 \times 30 \mathrm{~s}$ on ice, homogenates were centrifuged with $10,000 \mathrm{~g}$ at $4^{\circ} \mathrm{C}$ for $10 \mathrm{~min}$. The pellet was reextracted by sonication and both supernatants were pooled and concentrated under vacuum. The crude extract was stored until use at $-70^{\circ} \mathrm{C}$.

\section{Immunocytochemistry}

Immunocytochemical staining was performed on paraffin sections of the brains and adhering retrocerebral complexes of 160 foraging bees. After capture, workers were immobilized by cooling at $4^{\circ} \mathrm{C}$. Brains and retrocerebral complexes were dissected either out of the prefixed head after immediate perfusion with fixative or out of the head capsule and subsequently immersed in the fixative $(6 \%$ glutaraldehyde and $1 \%$ acetic acid in aqueous salurated picric acid). In three separate experimental series with five bees each, foragers were caught in the carly afternoon, kept individually at $12^{\circ} \mathrm{C}$ without feeding over night and dissected in the following morning. The explanted tissues were fixed at room temperature for 4-6h. Following dehydration and embedding in paraplast, serial sections $(12 \mu \mathrm{m})$ were cut and mounted on poly-lysine coated slides.

After rehydration, the sections were carefully washed in Tris-buffered saline (TBS: $0.3 \mathrm{M} \mathrm{NaCl}, 0.1 \mathrm{M}$ Tris- $\mathrm{HCl}, \mathrm{pH} \mathrm{7.6)}$ and then incubated in sodium borohydride solution $\left[1 \% \mathrm{NaBH}_{4}(\mathrm{w} / \mathrm{v})\right.$ in $0.1 \mathrm{M}$ Tris- $\left.\mathrm{HCl}\right]$ at room temperature for $30 \mathrm{~min}$. After three rinses in TBS, sections were incubated either in 5\% normal goat serum (NGS) or in the blocking solution of a Vectastain ABC-kit (Vector Laboratories) diluted in TBS plus $0.1 \%$ Triton X-100 (TBST) for $1 \mathrm{~h}$. The polyclonal rabbit antiserum against octopamine (cf. Eckert et al., 1992), a generous gift of J. Rapus and Dr M. Eckert (University of Jena, Germany), was diluted 1:800 in TBST plus 1\% NGS and applied on the sections at room temperature in a humidity chamber over night. Unbound serum was removed by three rinses with TBST. Specific binding of the antiserum was detected either by the PAP technique (Sternberger, 1979) by incubation in goat anti-rabbit immunoglobulin G (Sigma, 1:40 in TBST, $1 \mathrm{~h}$ ) followed by three washes in TBST and by incubation with rabbit peroxidase-antiperoxidase complex (Dakopatts, 1:100 in TBST, $1 \mathrm{~h}$ ). Alternatively, sections were treated according to the protocol given with the Vectastain ABCKit using TBST for the biotinylated secondary antibody and TBS for the ABC complex as dilution buffers. After

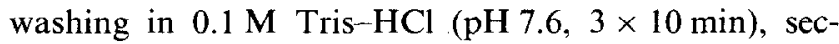
tions were treated with 3,3'-diaminobenzidine solution (Sigma, $0.2 \mathrm{mg} / \mathrm{ml}$ in Tris- $\mathrm{HCl}$ with $0.001 \% \quad \mathrm{H}_{2} \mathrm{O}_{2}$, 5-15 min). Finally, sections were washed, dehydrated in an ethanol series, cleared in xylene and mounted in Entellan (Merck).

Sections were viewed and photographed with a Poly- 
var microscope (Reichert-Jung). Schematic presentations were drawn from serial sections with the aid of a camera lucida.

Octopamine-like immunoreactivity in the $\mathrm{CA}$ was mapped with a computer aided microscope digitizer system (AutoCAD). The three dimensional pattern of stained structures was reconstructed from drawings of the successive serial sections. CA surfaces and vertically extending nerve processes were used to align adjacent sections. The 3-D reconstruction was then printed by generating two views with $3^{5}$ declination on the $3-\mathrm{D}$ object.

\section{Specificity controls}

The specificity of the employed anti-octopamine serum, raised in rabbits using octopamine coupled to thyroglobulin with glutaraldehyde, was originally characterized in the cockroach Periplaneta americana by Eckert et al. (1992) and meanwhile tested in several other arthropods (Stevenson et al., 1992; Nürnberger et al., 1993; Schneider et al., 1993). It does not crossreact with dopamine, noradrenaline and serotonin. For honey bee brain and retrocerebral complex sections, we performed the following controls: (a) incubation in the absence of primary antiserum; and (b) injection of $1 \mu \mathrm{g}$ reserpine per control bee to remove all biogenic amines from nervous tissue (Braun and Bicker, 1992) $12 \mathrm{~h}$ prior to dissection and complete immunocytochemical staining. Immunoreactivity was abolished by all control treatments.

\section{RESULTS}

\section{Effects of actopamine on $\mathrm{JH}$ production}

The kinetics of in vitro incorporation of the ${ }^{3} \mathrm{H}$-methyl moiety of methionine into JH by the CA was studied in nurse and foraging bees. After a lag phase of $20 \mathrm{~min}$, both stages released $\mathrm{JH}$ at constant rates for $6 \mathrm{~h}$ with 1.64 (nurse bees) and $5.30 \mathrm{pmol} \mathrm{JH} \cdot$ pair $\mathrm{CA}^{-1} \cdot \mathrm{h}^{-1}$ (foragers) (Fig. 1). Therefore we chose two successive incubation periods of $3 \mathrm{~h}$ each for the following experiments.

Treatments with $10^{-6} \mathrm{M}$ octopamine significantly stimulated production of $\mathrm{JH}$ by $\mathrm{CA}$ from nurse bees and foraging bees by 45.3 and $32.3 \%$, respectively, relative to the untreated controls (Fig. 2), but the enhanced JH production in young queenless workers was not affected (data not shown). Crude brain extracts from foraging bees resulted in an even higher increase of CA activity in the latter stage $(60.4 \%)$. The $15-20 \%$ increase of $\mathrm{JH}$ release in both control groups during the second incubation period is due to the lag-phase occurring in vitro during the first incubation period (cf. Fig. 1). Octopamine affected CA activity in a dose-dependent manner (Fig. 3). The threshold for this response laid between $10^{-7}$ and $10^{-8} \mathrm{M}$. Maximum stimulation in foraging bees occurred at $10^{-6} \mathrm{M}$ octopamine, but the effects by $10^{-5}$ and $10^{-7} \mathrm{M}$ octopamine, though weaker, did not differ significantly (U-test, $P<0.05$ ).

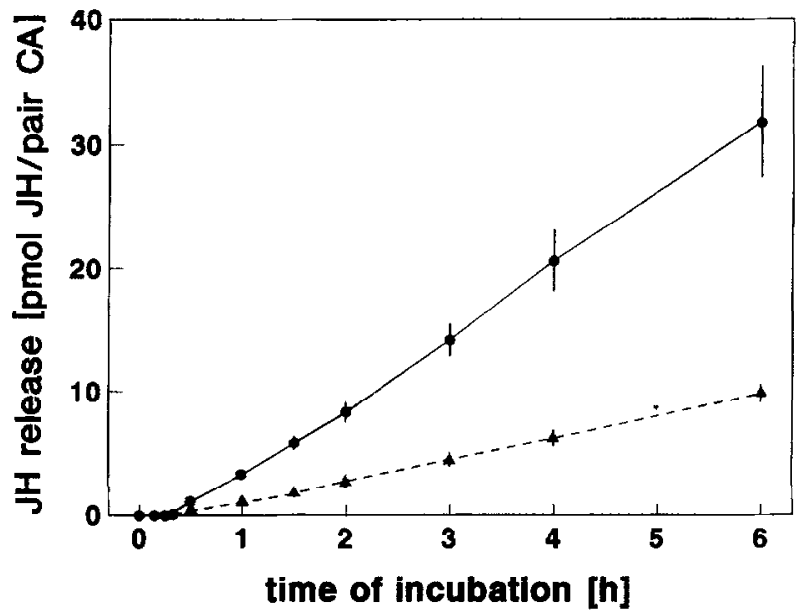

FIGURE 1. Kinetics of $\mathrm{JH}$ release by $\mathrm{CA}$ of nurse $(\boldsymbol{A})$ and foraging (O) bees in vitro. Each point represents the mean \pm SEM of 12-24 single pairs of CA. For the short time incubations $(10-30 \mathrm{~min})$, up to 6 pairs of $C A$ were coincubated in order to detect even minute amounts of released $\mathbf{J H}$.

\section{Octopamine-like immunoreactivity}

In order to analyse the occurrence and local distribution of octopamine in those parts of the nervous system that are considered to be involved in the regulation of $\mathrm{JH}$ biosynthesis in insects, we employed a specific antiserum against octopamine on serial sections of bee brains and retrocerebral complexes. Octopaminelike immunoreactivity was reproducibly detectable in the median neurosecretory cells (MNC), nervus corporis cardiaci (NCC) I, somata and varicose fibres of the corpora cardiaca $(\mathrm{CC})$ and nerve fibres surrounding the glandular cells of the CA of foraging becs, which were kept without food at $12^{\circ} \mathrm{C}$ over night [Fig. 4(a)]. In bees directly removed from the hive, immunolabelling of the above mentioned neuronal structures occurred in less than $5 \%$ of all analysed bees.

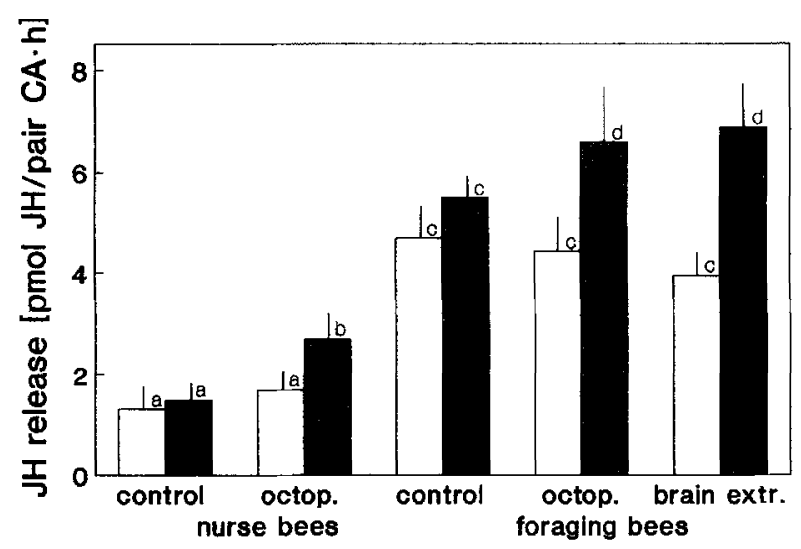

FIGURE 2. Stimulatory effect of octopamine and crude brain extracts on JH III biosynthesis of nurse and foraging bees. Two pairs of CA were coincubated for $3 \mathrm{~h}$ in normal medium to establish untreated rates of $\mathrm{JH}$ biosynthesis (open bars) and then incubated for $3 \mathrm{~h}$ with $10^{-6} \mathrm{M}$ octopamine or crude brain extracts (hatched bars). The results wcrc compared with a control group receiving only normal medium for both periods. Significant differences are denoted by different letters above the data columns (U-test, $P<0.05$ ). Mean \pm SEM, $n=8$. 


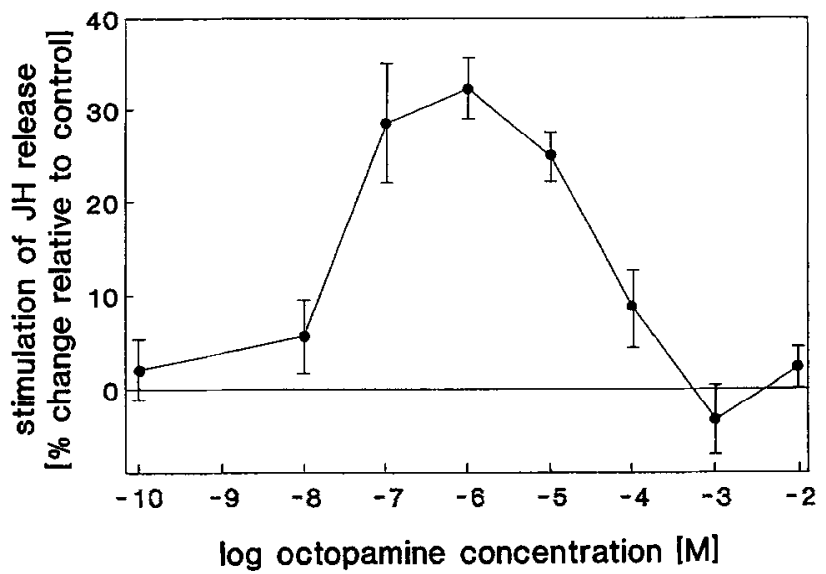

FIGURE 3. Dose-dependent effect of octopamine on JH release from $\mathrm{CA}$ of foraging bees. Same experimental conditions as described in Fig. 1. The percent change, relative to untreated controls during first incubation, is shown. Each point represents 6-12 determinations (mean + SEM, two pairs of CA per incubation).

Approximately 45 somata of the 120 median neurosecretory cells in the pars intercerebralis were immunoreactive [Fig. 4(b)]. These cells are ventrally located in the MNC cluster and are sporadically interspersed by unlabelled perikarya. Dorsally located MNC just as lateral neurosecretory cells and their respective nerve projections, the NCC II, were never labelled with the antibody. Immunoreactivity was also visible in the protocerebral central body [Fig. 4(b)].

Processes leaving the cell bodies of the labelled MNC project via immunolabelled NCC I into the $\mathrm{CC}$ [Fig. 4(b)]. The CC contain densely packed immunoreactive varicose structures in the ventral half [Fig. 4(c and d)]. In their immediate vicinity we found 8-10 intensely stained elliptoid somata with unstained nuclei. They are smaller $(<5 \mu \mathrm{m}$ wide) than and separated from the unlabelled relatively large intrinsic glandular corpus cardiacum cells ( $>10 \mu \mathrm{m}$ across) and their cell processes were hardly discernible [Fig. 4(d)]. Immunolabelled varicose fibres also terminated in the most dorsally located group of large glandular cells.

In the CA very fine octopamine-immunoreactive nerve fibres with varicose terminals surround each of the gland cells forming a branched neuronal network in the gland tissue [Fig. 4(e and f)].

\section{Starvation and $J H$ biosynthesis}

Since octopamine-like immunoreactivity was consistently obtained when bees were starved, we compared $\mathrm{CA}$ activity of bees kept under such experimental conditions with those in normal colonies. JH release increased 1.81 times in foragers and even 7.07 times in nurse bees (Fig. 5), reaching maximum mean rates of 9.05 and $10.11 \mathrm{pmol} \mathrm{JH} \cdot$ pair $\mathrm{CA}^{-1} \cdot \mathrm{h}^{-1}$ in vitro, respectively, far above the values, which were ever observed in bees under normal colony conditions.

\section{DISCUSSION}

Our results clearly demonstrate that octopamine stimulates $\mathrm{JH}$ release by explanted CA of adult honey bees. Since JH release is linearily correlated with $\mathrm{JH}$ biosynthesis by $\mathrm{CA}$ in vitro and reflects the $\mathrm{JH}$ titres in the haemolymph (Huyang et al., 1991), it provides an accurate estimate for $\mathrm{JH}$ biosynthesis in adult worker honey bees. Thus, we assume that this biogenic amine also stimulates biosynthesis of $\mathrm{JH}$ in vivo. Octopamine effects on $\mathrm{JH}$ release have been previously only demonstrated in a locust (Lafon-Cazal and Baehr, 1988) and in a cockroach (Thompson et al., 1990). The bell shaped dose-response curve shows striking similarities to that of octopamine on the neuronal activity in the visual system of the honey bee (Erber et al., 1991). Octopamine concentrations above $10{ }^{4} \mathrm{M}$ are ineffective in both target tissues. The reason for the observed ineffectiveness, however, remains a matter for speculation. Since serotonin is the prominent antagonist of octopamine in the bec (Erber et al., 1993), onc might argue, among numerous other possibilities, that octopamine acts in high concentrations on serotoninergic receptors that mediate inhibition of $\mathrm{JH}$ biosynthesis.

The observed effect of octopamine on CA activity coincides with the octopamine-like immunoreactivity which was found for the first time in insects in some of the neuroendocrine tissues such as neurosecretory cells and $\mathrm{CC}$ that are considered to be involved in the regulation of JH biosynthesis (Tobe and Stay, 1985; Thompson and Tobe, 1990; Duve et al., 1991; Stay et al., 1992). To date octopamine was found to be present in insect neurosecretory tissues only by the use of biochemical methods (cf. David and Coulon, 1985). Octopaminelike immunoreactivity, however, was recently detected in segmentally arranged neurosecretory cells of the ventral nerve cord in lobsters (Schneider et al., 1993). By means of the same antibody we found an immunoreactive group of about 45 of the 120 cells of the median neurosecretory cell complex in the Pars intercerebralis of the bees. But the recently discovered lateral neurosecretory cells (Eichmüller et al., 1991) and their nerve projections did not react immunocytochemically. The MNC do not bind considerable amounts of $\left[{ }^{3} \mathrm{H}\right]$ octopamine as studied with autoradiographic methods (Scheidler, 1991) and, thus, are probably not target sites for this amine. It appears that the immunopositive MNC project via NCC I into the CC. The NCC I fuses in the ventral protocerebrum with the lateral and median fibres of the NCC II to form the NCC of the honey bee (Eichmüller et al., 1991).

We detect heavily stained varicose structures and somata in the ventral part of the $\mathrm{CC}$. The relatively small cells have not been described before and differ in size and shape from the large intrinsic glandular cells especially those 24, which contain adipokinetic hormone-like peptides in Apis (Schooneveld et al., 1987). Octopaminergic innervation of the $\mathrm{CC}$ has been proposed in insects in the light of biochemical evidence for the presence of octo- 

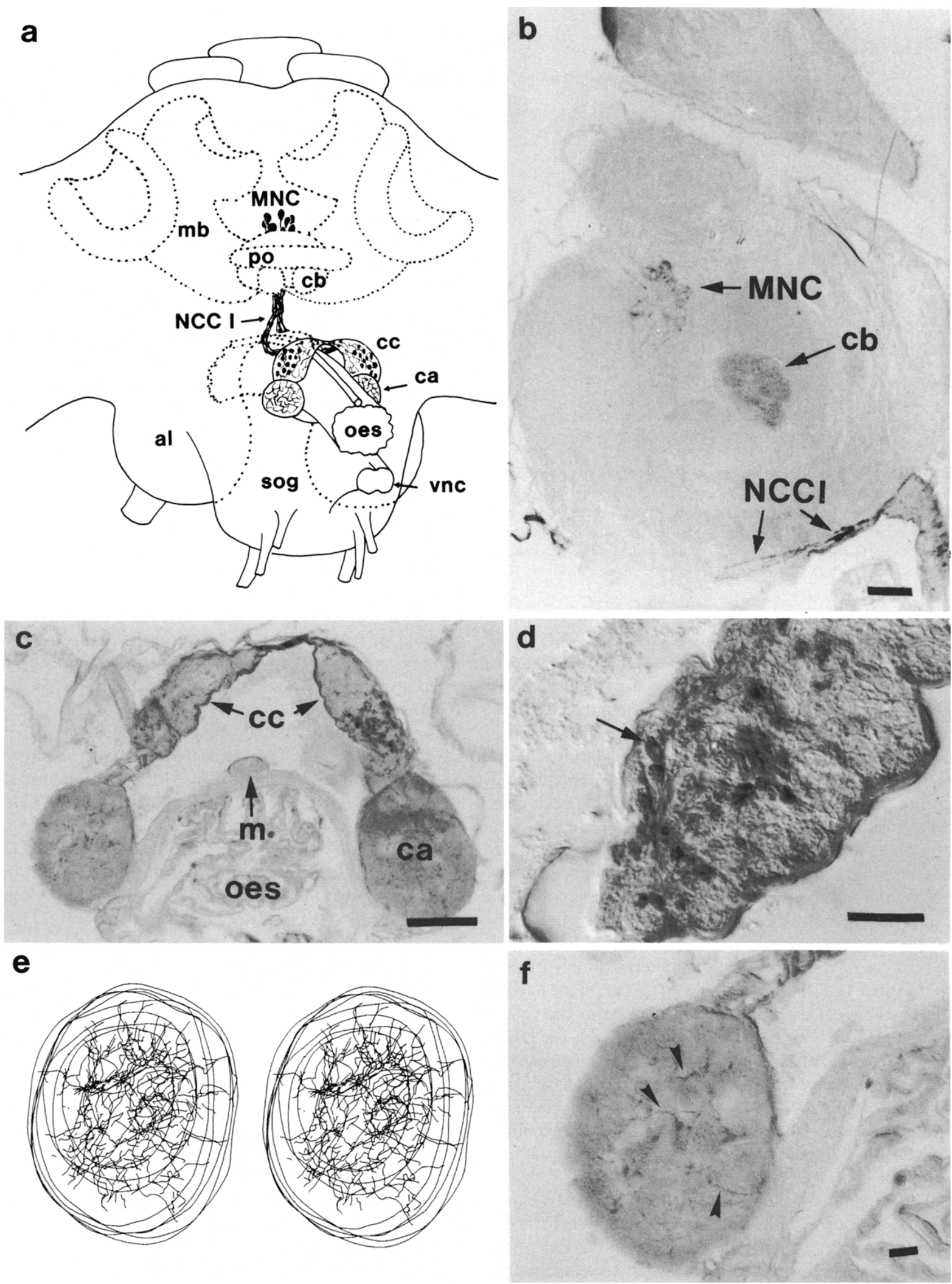

FIGURE 4. Immunocytochemical reactivity of the median neurosecretory cells and the retrocerebral complex to antiserum against octopamine. (a) Summary reconstruction of octopamine-like immunoreactivity in median neurosecretory cells and retrocerebral complex. Posterior view. Fibres originating from the median neurosecretory cells in the pars intercerebralis project into the corpora cardiaca via NCC I. (b) Median sagittal section documents immunolabelling of large sized somata of median neurosccretory cells. Labelled fibres originating in these cells project into the corpora cardiaca via NCC I (arrows). Scale bar: $50 \mu \mathrm{m}$ (c) Retrocerebral complex. Scale bar: $50 \mu \mathrm{m}$. (d) Corpus cardiacum lobe with immunolabelled varicose structures and somata (arrow). Scale bar: $10 \mu \mathrm{m}$. (e and $\mathrm{f}$ CA with immunoreactive nerve fibres (arrowheads) surrounding the glandular cells. Scale bar: $10 \mu \mathrm{m}$. (e) Computerized 3-D reconstruction. Abbreviations: al, antennal lobe; ca, corpora allata: cb, central body; cc, corpora cardiaca: mb, mushroom bodies; MNC, median neurosecretory cells; NCC I. nervus corporis cardiaci 1; oes, oesophagus; po. pons of the central body complex (protocerebral bridge); rn, recurrent nerve; sog, suboesophagial ganglion; vne, ventral nerve cord. 


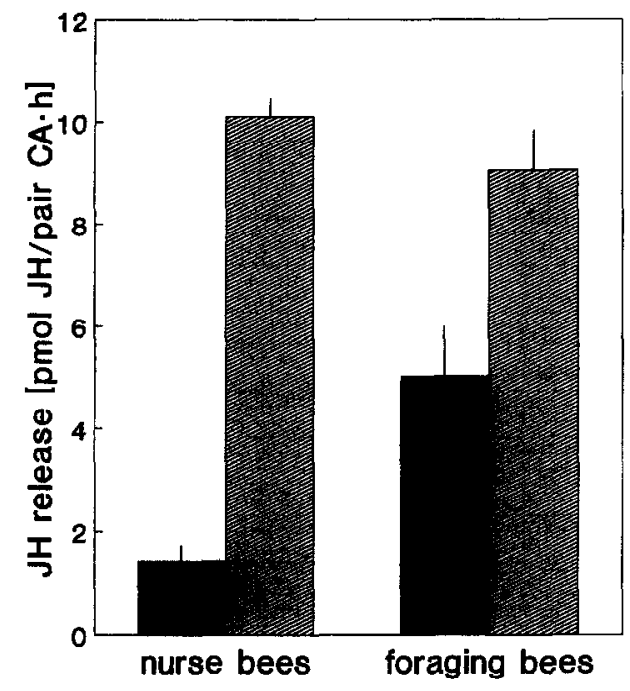

FIGURE 5. Effect of starvation on $\mathrm{JH}$ production in nurse and foraging bees. Bees were caught and kept individually without feeding at $12^{\circ} \mathrm{C}$ over night. In the following morning, $\mathrm{CA}$ of individual bees were explanted and incubated by pairs. Treatment results in a significant increase of $\mathrm{JH}$ release (hatched bars) compared to untreated controls (closed bars) in both stages (U-test, $P<0.05$, mean \pm SEM, $n=12$ ).

pamine in the CC (David and Lafon-Cazal, 1979; Orchard et al., 1986) and the pharmacological evidence for the involvement of octopamine in the release of neuropeptides from the intrinsic glandular cells (Pannabecker and Orchard, 1986). Strongest evidence for an involvement of octopamine in the regulation of CA activity, however, originates from a octopamine-like immunoreactive neuronal network surrounding each glandular cell of the CA. By solely following the immunocytochemical staining in the fine fibres seen in the CA we could not conclusively decide whether some of the octopamine-like neurons in the pars intercerebralis, that extend axons to the $\mathrm{CC}$, innervate the $\mathrm{CA}$, or whether the intrinsic immunopositive neurons in the $\mathrm{CC}$ have terminals in the CA, or both. Octopaminergic innervation of the CA in insects has been proposed earlier on the basis of the biochemical detection of octopamine in the CA of locusts (Evans, 1978; David and Lafon-Czal, 1979) and cockroaches (Evans, 1978) and recently based on electrophysiological experiments demonstrating that electrical stimulation of the NCA as well as octopamine treatment elicits hyperpolarization of CA cells, which can be inhibited by the octopamine receptor blocker phentolamine (Thompson et al., 1990).

The present first detection of octopamine-like immunoreactive structures in the neuroendocrine system in insects is without a doubt dependent on the starvation of the bees. Previous approaches in untreated cockroaches $(H$. Agricola, personal communication) and locusts (Konings et al., 1988) failed. P. A. Stevenson (personal communication), however, detected immunopositive $\mathrm{MNC}$ in $\mathrm{Lo}-$ custa migratoria once these animals were starved. Starvation is known to increase octopamine levels in the brain of the locust Schistocerca gregaria (Davenport and Evans, 1984). Elevated levels of octopamine were also found in a number of insects including honey bees in response to stress (cf. Harris and Woodring, 1992) and seem to prepare the animal for intense activity (Corbett, 1991). Thus, it is likely that the amount of octopamine in $\mathrm{MNC}, \mathrm{CC}$ and $\mathrm{CA}$ is elevated due to starvation above the detcetion threshold of the applied immunocytochemical method. The sensitivity of the immunostaining with the antibody as studied in the lobster nervous system amounts to $14 \mathrm{fmol}$ per cell body (Schneider et al., 1993). In the light of our experiments on the explanted CA may such an increase in octopamine content, supposing the amine is released, result in an enhanced $\mathrm{JH}$ production. Such an increase in CA activity is actually detectable in starved bees reaching a level that is higher than ever found in any behavioural and physiological state in Apis (Hildebrandt and Kaatz, 1990, 1992; Rachinsky and Hartfelder, 1990; Huang et al., 1991; Huang and Robinson, 1992; Kaatz et al., 1992b; Robinson et al., 1992). The observed increase in $\mathrm{JH}$ production in both nurse and foraging bees after starvation may accelerate the transition of nurse bees to foraging bees or intensify foraging activity, respectively, as $\mathrm{JH}$ is involved in the control of age polyethism in worker bees and treatment with $\mathrm{JH}, \mathbf{J H}$ mimics or analogues induces precocious foraging. Especially in colonies that lack, due to experimentation, foragers, nurse bees turn within 2 days into active foragers after a premature rise in $\mathrm{JH}$ haemolymph titres (cf. Robinson, 1992).

Both, physiological and immunocytochemical, observations suggest that octopamine plays a role in the control of JH biosynthesis by the CA in vivo. The present experiments, however, have not determined whether octopamine affects the activity of the CA neuronally via (i) direct effect on the intrinsic cells of the CA, and/or (ii) modulation of the release of neurotransmitters or neurohormones from the many nerve terminals in the CA, or (iii) humorally via circulating levels of octopamine. Evidence from other insects is not yet conclusive either. A direct octopaminergic innervation of the CA was already proposed by Thompson et al. (1990), based on the finding that hyperpolarization of the $\mathrm{CA}$, evoked by electrical stimulation of the NCA or by octopamine, was blocked by the $\alpha$-adrenergic receptor blocker phentolamine in Diploptera punctata. The present immunocytochemical evidence substantiates this hypothesis as it suggests that octopamine is involved in the neuronal control of the CA activity in Apis probably being released in the immediate vicinity of the adjacent gland cells. But octopamine is presumably not the sole allatotropin acting on JH biosynthesis in bees, since it stimulates $\mathbf{J H}$ release of explanted CA from foraging bees merely by $32 \%$, whereas brain extracts enhance $\mathrm{JH}$ production by $60 \%$. This indicates that other, yet unknown factors besides this amine are involved in the stimulation of CA activity. Also, the large increase in the rates of $\mathrm{JH}$ biosynthesis after starvation (Fig. 5), especially in the case of nurse bees, is probably not only due to an octopamine exposure in vivo. Primary candidates are allatotropic neuropeptides which have been recently characterized in Manduca sexta (Kataoka 
et al., 1989). They may directly affect $\mathrm{JH}$ biosynthesis or interact with octopamine. Their release from putative peptidergic neurons could be modulated by octopamine, since it is known that this amine is able to mediate neuropeptide release in other insects (Pannabecker and Orchard, 1986). Although octopamine-like immunoreactivity found in nerve terminals of the CA suggests a neuronal control, JH biosynthesis could also be controlled, at least in part, by circulating levels of octopamine. Especially since octopamine is released into the haemolymph in insects, acts as a neurohormone and is elevated especially during stress and flight (cf. Orchard et al., 1993). Such a humoral mode of action would coincide with the detected octopamine-like varicosities and somata in the $\mathrm{CC}$ that presumably function as neurohaemal organs. Future studies will elucidate the functional significance of octopamine as a neuromodulator controlling the release of allatoregulatory neuropeptides or as a neurohormone, directly altering the $\mathrm{JH}$ production.

\section{REFERENCES}

Agricola H., Hertel W. and Penzlin H. (1988) Octopamin-Neurotransmitter. Neuromodulator, Neurohormon. Zool Jb. Physiol. 92, l-45.

Bicker G. and Menzel R. (1989) Chemical codes for the control of behaviour in arthropods. Nature 337, 33-39.

Brandes C., Sugawa M. and Menzel R. (1990) High performance liquid chromatography (HPLC) measurement of catecholamines in single honeybee brains reveals caste-specific differences between worker bees and queens in Apis mellifera. Comp. Biochem. Physiol. 97C, $53-57$.

Braun G. and Bicker G. (1992) Habituation of an appetitive reflex in the honeybee. J. Neurophvsiol. 67, 588-598.

Corbett S. A. (1991) A fresh look at the arousal syndrome in insects. Adi. Insect Physiol. 23, 81-116.

Davenport A. P. and Evans P. D. (1984) Changes in haemolymph octopamine levels associated with food deprivation in the locust, Schistocerca gregaria. Physiol. Ent. 9, 269-274.

David J. C. and Coulon J. F. (1985) Octopamine in invertebrates and vertebrates. A review. Progr. Neurobiol. 24, 141-185.

David J. C. and Lafon-Cazel M. (1979) Octopamine distribution in the Locusta migratoria nervous and non-nervous systems. Comp. Biochem. Physiol. 64C, 161-164.

Duve H.. Thorpe A. and Tobe S. S. (1991) Immunocytochemical mapping of neuronal pathways from the brain to corpora cardiaca/corpora allata in the cockroach Diploptera punctata with antisera against Met-enkephalin-Arg ${ }^{6}-\mathrm{Gly}^{7}-\mathrm{Leu}^{8}$. Cell Tissue Res. 263, 285-291.

Duve H., Johnsen A. H., Scott A. G., Yu C. G., Yagi K. J., Tobe S. S. and Thorpe A. (1993) Callatostatins: Neuropeptides from the blowfly Calliphora comitoria with sequence homology to cockroach allatostatins. Proc. natn. Acad. Sci. U.S.A. 90, 2456-2460.

Eckert M., Rapus J., Nürnberger A. and Penzlin H. (1992) A new specific antibody reveals octopamine-like immunoreactivity in cockroach ventral nerve cord. J. comp. Neurol. 322, 1-15.

Eichmüller S., Hammer M. and Schäfer S. (1991) Neurosecretory cells in the honeybee brain and suboesophageal ganglion show FMRFamide-like immunoreactivity. J. comp. Neurol. 312, 164-174.

Erber J., Kloppenberg P. and Scheidler A. (1991) Neuromodulation in the honeybee: autoradiography, behaviour and clcctrophysiology. In The Behaviour and Physiology of Bees (Eds Goodman L. J. and Fischer R. C.), pp. 273-287. CAB International, Wallingford.

Erber J., Kloppenburg P. and Scheidler A. (1993) Neuromodulation by serotonin and octopamine in the honeybee: behaviour, neuroanatomy and electrophysiology. Experientia 49, 1073-1083.
Evans P. D. (1978) Octopamine distribution in the insect nervous system. J. Neurochem. 30, 1009-1013.

Evans P. D. (1985) Octopamine. In Comprehensive Insect Physiology, Biochemistry and Pharmacology (Eds Kerkut G. A. and Gilbert L. I.), Vol. 11, pp. 499-530. Pergamon Press, Oxford.

Feyereisen R. and Tobe S. S. (1981) A rapid partition assay for routine analysis of juvenile hormone release by insect corpora allata. Analyt. Biochem. Physiol. 92C, 337-342.

Fuchs E., Dustmann J. H., Stadler H. and Schürmann F. W. (1989) Neuroactive compounds in the brain of the honeybee during imaginal life. Comp. Biochem. Physiol. 92c, 337-342.

Harris J. W. and Woodring J. (1992) Effcets of stress, age, season and source colony on levels of octopamine, dopamine and serotonin in the honey bee (Apis mellifera L.). J. Insect Phvsiol. 38, 29-35.

Hildebrandt H. and Kaatz H.-H. (1990) Impact of queen pheromone on the physiological status of worker honey bees. In Social Insects and the Environment (Eds Veeresh G. K., Mallik B. and Viraktamath C. A.), pp. $740-741$. IBH, New Dehli.

Hildebrandt H. and Kaatz H.-H. (1992) Antennal perception of the honey bee queen pheromone and its effect on juvenile hormone biosynthesis in workers. In Insect Juvenile Hormone Research: Fundamental and Applied Approaches (Eds Mauchamp B., Couillaud F. and Baehr J. C.), pp. 73-82. INRA, Paris.

Huang Z.-Y. and Robinson G. E. (1992) Honeybee colony integration worker-worker interactions mediate hormonally regulated plasticity in division of labor. Proc. natn. Acad. Sci. U.S.A. 89, 11726-11729.

Huang Z.-Y.. Robinson G. E., Tobe S. S., Yagi K. J., Strambi C., Strambi A. and Stay B. (1991) Hormonal regulation of behavioural development in the honey bee is based on changes in the rate of juvenile hormone biosynthesis. J. Insect Physiol. 37, 733-741.

Kaatz H. H., Hagedorn H. H. and Engels W. (1985) Culture of honey bee organs: development of a new medium and the importance of tracheation. In Vitro Cell. Dev. Biol. 21, 347-352.

Kaatz H. H., Engels. W. Fischer L. C. and Hildebrandt H. (1992a) Pheromonal control of oogenesis in worker honey bees. In Advances in Regulation of Insect Reproduction (Eds Bennetová B., Gelbic I. and Soldán T.). pp. 135-140. Czech. Acad. Sci.

Kaatz H. H., Hildebrandt H. and Engels W. (1992b) Primer effect of queen pheromone on juvenile hormone biosynthesis in adult worker honey bees. J. comp. Physiol. B162, 588-592.

Kataoka H., Toschi A., Li J. P., Carney R. L., Schooley D. A. and Kramer S. J. (1989) Identification of an allatotropin from adult Manduca sexta. Science 243, $1481 \cdot 1483$.

Konings P. N. M., Vullings H. G. B., Deffard M., Buijs R. M., Diederen J. H. B. and Jansen W. F. (1988) Immunocytochemical demonstration of octopamine-immunoreactive cells in the nervous system of Locusta migratoria and Schistocerca gregaria. Cell Tissue Res. 251, 371-379.

Kramer S. J., Toschi A., Miller C. A., Kataoka H., Quistad G. B., Li J. P., Carney R. L. and Schooley D. A. (1991) Identification of an allatostatin from the tobacco hornworm Manduca sexta. Proc. natn. Acad. Sci. U.S.A. 88, 9458-9462.

Lafon-Cazal M. and Baehr J. C. (1988) Octopaminergic control of corpora allata activity in an insect. Experientia 44, 895-896.

Maurizio A. (1954) Pollenernährung und Lebensvorgänge bei der Honigbiene (Apis mellifica L.). Landwirtsch. Jh. Schweiz 68, $115-182$.

Mercer A. (1987) Biogenic amines and the bee brain. In Neurobiolog. and Behaviour of Honeybees (Eds Menzel R. and Mercer A.). pp. 244-252. Springer Verlag, Berlin

Mercer A. R., Mobbs P. G., Davenport A. P. and Evans P. D. (1983) Biogenic amines in the brain of the honeybee, Apis mellifera. Cell Tissue Res. 234, 655-677.

Nürnberger A., Rapus J., Eckert M. and Penzlin H. (1993) Taurinelike immunoreactivity in octopaminergic neurons in the cockroach (Periplaneta americana L.). Histochemistry 100, 285-292.

Orchard I., Gole I. W. D., Sloley B. D. and Downer R. G. H. (1986) The association of 5-hydroxytryptamine, octopamine, and dopamine with the intrinsic (glandular) lobe of the corpus cardiacum of Locusta migratoria. Can. I. Zool. 64, $271-274$. 
Orchard I., Ramirez J.-M. and Lange A. B. (1993) A multifunctional role for octopamine in locust flight. A. Rev. Ent. 38, 227-249.

Pannabecker T. and Orchad I. (1986) Octopamine and cyclic AMP mediate release of adipokinetic hormone I and II from isolated locust neuroendocrine tissue. Molec. Cell Endocr. 48, 153-159.

Pratt G. E. and Tobe S. S. (1974) Juvenile hormones radiobiosynthesised by corpora allata of adult female locusts in vitro. Life Sci. 14, 575-586.

Pratt G. E., Farnsworth D. E., Fok K. F., Siegel N. R., McCormack A. L., Shabanowitz J., Hunt D. F. and Feyereisen R. (1989) Identity of a second type of allatostatin from cockroach brains: An octadecapeptide amide with tyrosine-rich address sequence. Proc. natn. Acad. Sci. U.S.A. 88, 2412-2416.

Pratt G. E., Farnsworth D. E., Siegel N. R., Fok K. F. and René Feyereisen (1989) Identification of an allatostatin from adult Diploptera punctata. Biochem. Biophys. Res. Commun. 163, 1243-1247.

Rachinsky A. and Hartfelder K. (1990) Corpora allata activity, a prime regulating element for caste-specific juvenile hormone titre in honey bee larvae (Apis mellifera carnica). J. Insect Physiol. 36, 189-194.

Rembold H. (1987) Caste specific modulation of juvenile hormone titers in Apis mellifera. Insect Biochem. 17, 1003-1006.

Robinson G. E. (1992) Regulation of division of labor in insect societies. A. Rev. Ent. 37, 637-665.

Robinson G. E., Strambi C., Strambi A. and Huang Z.-Y. (1992) Reproduction in worker honey bees is associated with low juvenile hormone titers and rates of biosynthesis. Gen. comp. Endocr. 87, $471-480$.

Scheidler A. (1991) Autoradiographische Darstellung von Bindungsstellen für verschiedene Neurotransmitter-Kandidaten im Gehirn der Honigbiene (Apis mellifera L.). Doctoral thesis Technical University Berlin.

Schooneveld H., Romberg-Privee H. M. and Veenstra J. A. (1987) Phylogenetic differentiation of glandular cells in corpora cardiaca as studied immunocytochemically with region-specific antisera to adipokinetic hormone. J. Insect Physiol. 33, 167-176.

Schneider H., Trimmer B. A., Rapus J., Eckert M., Valentine D. E. and Kravitz E. A. (1993) Mapping of octopamine-immunoreactive neurons in the central nervous system of the lobster. J. comp. Neurol. 329, 129-142.

Stay B., Chan K. K. and Woodhead A. P. (1992) Allatostatin-immunoreactive neurons projecting to the corpora allata of adult Diploptera punctata. Cell Tissue Res. 270, 15-23.

Sternberger L. A. (1979) Immunocytochemistry, 2nd edn. Wiley, New York.

Stevenson P. A., Pflüger H.-J., Eckert M. and Rapus J. (1992) Octopamine immunoreactive cell populations in the locust thoracicabdominal nervous system. $J$. comp. Neurol. 315, 382-397.

Taylor D. J., Robinson G. E., Logan B. J., Laverty R. and Mercer A. R. (1992) Changes in brain amine levels associated with the morphological and behavioural development of the worker honeybee. J. comp. Physiol. A 170, 715-721.

Thompson C. S. and Tobe S. S. (1990) Innervation and electrophysiology of the corpus allatum. In Cockroaches as Models for Neurobiology: Applications in Biomedical Research (Eds Huber I., Masler E. P. and Rao B. R.), Vol. 1, pp. 89-101. CRC Press, Boca Raton, FL

Thompson C. S., Yagi K. J., Chen Z. F. and Tobe S. S. (1990) The effects of octopamine on juvenile hormone biosynthesis, electrophysiology, and cAMP content of the corpora allata of the cockroach Diploptera punctata. J. comp. Physiol. B 160, 241-249.

Tobe S. S. and Stay B. (1985) Structure and regulation of the corpus allatum. Adv. Insect Physiol. 18, 305-432.

Woodhead A. P., Stay B., Seidel S. L., Khan M. A. and Tobe S. S. (1989) Primary structure of four allatostatins: neuropeptide inhibitors of juvenile hormone synthesis. Proc. natn. Acad. Sci. U.S.A. 86, $5997-6001$.

Acknowledgements-We thank J. Rapus and M. Eckert for the generous gift of the octopamine-antiserum, J. Erber, H. H. Hagedorn and $J$. Veenstra for helpful discussions. We also like to thank the $E . H$. Erickson and the USDA-Carl-Hayden Hee Research Center for providing bees and lab space. The study was supported by grants from the Deutsche Forschungsgemeinschaft (DFG, Bi 262/3-2, Ka 1035/1-2, Me 365/16-1). 